\title{
Article \\ Reliability-as-a-Service Usage of Electric Vehicles: Suitability Analysis for Different Types of Buildings
}

\author{
Akhtar Hussain ${ }^{1}$ and Petr Musilek ${ }^{1,2, *}$ (D) \\ 1 Department of Electrical and Computer Engineering, University of Alberta, Edmonton, AB T6G 2G2, Canada; \\ akhtar3@ualberta.ca \\ 2 Department of Applied Cybernetics, University of Hradec Králové, 50003 Hradec Králové, Czech Republic \\ * Correspondence: pmusilek@ualberta.ca
}

Citation: Hussain, A.; Musilek, P. Reliability-as-a-Service Usage of Electric Vehicles: Suitability Analysis for Different Types of Buildings. Energies 2022, 15, 665. https:// doi.org/10.3390/en15020665

Academic Editor: Adolfo Dannier

Received: 8 December 2021

Accepted: 12 January 2022

Published: 17 January 2022

Publisher's Note: MDPI stays neutral with regard to jurisdictional claims in published maps and institutional affiliations.

Copyright: (c) 2022 by the authors. Licensee MDPI, Basel, Switzerland. This article is an open access article distributed under the terms and conditions of the Creative Commons Attribution (CC BY) license (https:// creativecommons.org/licenses/by/ $4.0 /)$.

\begin{abstract}
The use of electric vehicles (EVs) to provide different grid services is becoming possible due to the increased penetration levels, mileage efficiencies, and useable battery sizes of EVs. One such application is providing reliability-as-a-service (RaaS) during short-term power outages. Instead of using a dedicated backup power source, EVs can be contracted to provide RaaS, which is an environmentally friendly solution with benefits for both building owners and EV owners. However, the presence of EVs at a particular location during different hours of the day and the availability of energy from EVs is uncertain. Therefore, in this study, a suitability analysis is performed concerning the use of EVs to provide RaaS for different types of buildings. First, the National Household Travel Survey (NHTS) survey data are used to estimate driver behavior, such as arrival/departure times, daily mileage, and traveling duration. Then, the usable battery size and mileage efficiency of EVs is extracted from the database of commercially available EVs. Based on these parameters, the daily energy consumption and available energy of EVs to provide RaaS are estimated. A suitability analysis is conducted for residential, commercial/industrial, and mixed buildings for both weekdays and holidays. The participation ratio of EV owners is varied between 10 and $90 \%$, and nine cases are simulated for commercial/industrial buildings and multi-unit residential buildings. Similarly, the ratio of home-based EVs is varied between 5 and $50 \%$, and 10 cases are tested for mixed buildings. The analysis shows that mixed buildings are the most suitable, while commercial/industrial buildings are the least suitable for using EVs to provide RaaS. To this end, an index is proposed to analyze and determine the desired ratio of EVs to be contracted from homes and workplaces for mixed buildings. Finally, the impact of EV fleet size on the available energy for RaaS is also analyzed.
\end{abstract}

Keywords: backup power; electric vehicle; home and workplace; power outage; reliability-as-aservice; suitability analysis; vehicle-to-grid

\section{Introduction}

A continuous supply of electricity is required in all sectors not only to run daily routine activities but also to keep critical services functional during loss of connection with the grid. Loss of connection could be due to either reliability-oriented events or resilience-oriented events. The former refers to small-scale outages with a typical duration of minutes to hours, while the latter refers to large-scale outages with a typical duration of hours to days [1]. In the case of resilience-oriented events, residents may need to evacuate, and other infrastructure may also be compromised. During reliability events, there is no emergency except temporary loss of connection to the grid due to the failure of a line or a generation unit [2]. Therefore, backup generators are generally used in buildings, especially multi-unit buildings, to keep the required services running during power-outage periods. The use of backup power resources is common both in the residential and commercial sectors [3]. Diesel generators are the most commonly used backup generators due to their relatively lower initial costs and higher energy density [4]. However, diesel generators are not environmentally friendly and require proper maintenance throughout the year [5]. 
Recently, the battery energy storage system (BESS) has been considered as an alternative green option to serve as a backup power source [6]. However, the upfront cost of BESS is higher, and the frequency of outage events is low, i.e., about nine hours per year [7]. BESS needs to be installed and maintained throughout the year to prepare for such events. This results in increased costs for building owners/operators. Meanwhile, the penetration of electric vehicles (EVs) is increasing in the transport sector, and the global EV fleet is projected to reach between 140 and 245 million by 2030 [8]. In addition, the useable battery size and energy consumption efficiency of EVs are also increasing [9]. This provides opportunities for using EVs to provide reliability-as-a-service (RaaS) during reliability-oriented events. The use of EVs to provide RaaS could be especially beneficial for multi-unit residential buildings or commercial/industrial buildings where several cars are parked together in a shared parking location.

The use of EVs to provide RaaS will be beneficial for both building and EV owners. It will reduce investment and operation costs for building owners while creating additional revenues for EV owners. Several studies have been conducted on the use of EVs to provide different services to power grids, such as peak shaving [10], frequency regulation [11], and voltage control [12]. The economic benefits of different vehicle-to-grid (V2G) services are analyzed in [13], and the benefits of V2G services in renewable-coupled systems are analyzed in [14]. However, these services are required on daily basis in power systems, and EVs need to be called frequently. This could increase battery degradation, which is considered one of the main obstacles in registering for any V2G program [15]. However, due to the lower frequency of reliability events, RaaS usage of EVs can be considered a practical solution. In addition, EV owners can contract for the amount of energy they can provide per year/event based on their daily mileage and the desired minimum state-of-charge (SoC) level in the EV.

To assess the economic feasibility of using EVs to provide RaaS, the authors conducted an initial study [16]. A reward mechanism is proposed to provide incentives to EV owners to register and comply with their RaaS contracts. In addition, yearly revenue for EV owners is estimated under extreme cases, i.e., no events and one event per month. Results have shown that using EVs can reduce costs for building operators as compared to diesel generators and BESS, while generating additional revenue for EV owners. However, there are several uncertainties associated with EVs compared to dedicated backup resources (diesel generators and BESS), which are as follows:

- The presence of EVs in a particular location during different hours of the day varies, leading to uncertainty.

- The amount of energy available from each EV to provide RaaS during any event is uncertain.

- The probability of the presence of EVs in a particular location could be different for weekdays and holidays, especially for workplaces.

- The percentage of EV owners willing to participate in the RaaS program could also vary from location to location.

Therefore, a stochastic analysis is required to determine the potential of using EVs to provide RaaS. Several factors, such as EV parameters (battery size, mileage efficiency, and $\mathrm{SoC}$ ), EV driver behavior (daily mileage, arrival and departure times, required energy for upcoming trips, etc.), building types (residential, commercial/industrial, and mixed), and day types (working days and holidays) must be considered. This information can be used to determine the suitability of RaaS usage of EVs for different building types. In addition, the number of EVs required to provide a certain amount of energy for different types of days should also be determined.

Based on the insights gained from the economic feasibility analysis [16], the suitability analysis concerning the use of EVs to provide RaaS is carried out in this study. To capture the stochastic behavior of vehicle owners, the U.S. National Household Travel Survey (NHTS) dataset [17] is used, and different parameters are estimated. These parameters include home/workplace arrival/departure times, daily mileage of vehicles, and duration 
of trips. In addition, the parameters of EVs are extracted from the database of commercially available EVs [18] to date. These parameters include the useable battery size and the energy consumption efficiency of EVs. Then, a suitability analysis concerning the use of EVs to provide RaaS for residential, commercial/industrial, and mixed buildings with shared parking spaces is carried out. The analysis is conducted for both weekdays and holidays. An index is also proposed to analyze the variations in the available energy of EVs for RaaS at different hours of the day. Then, the desired ratio of EVs to be contacted from homes and workplaces is determined for mixed buildings. The objective of this index is to minimize the variation in available energy to be used simultaneously as backup power for both weekdays and holidays.

\section{Parameter Extraction from NHTS Data}

To estimate the amount of energy available in EVs to provide RaaS for different buildings, two types of data are required. The first category of data is related to the behavior of vehicle drivers, and the second category is related to EVs. In this section, data related to vehicle drivers are discussed. These data include the daily mileage of vehicles, the arrival/departure time of vehicles at home/workplace, and the stay hours at home/workplace. These are stochastic parameters, and a large and reliable dataset is required due to differences in the social dynamics and personal preferences of vehicle drivers [19]. Such a dataset is not yet available for EVs. Therefore, the NHTS dataset [17] is used in this study to extract these parameters, as shown in Figure 1. The survey dataset contains 923,572 trip datapoints for 117,222 households with 203,007 vehicles. This dataset is considered reliable, and it has been used by several researchers for EV load estimation [20,21]. The extracted data are then translated into EVs, which will be discussed in the next section.

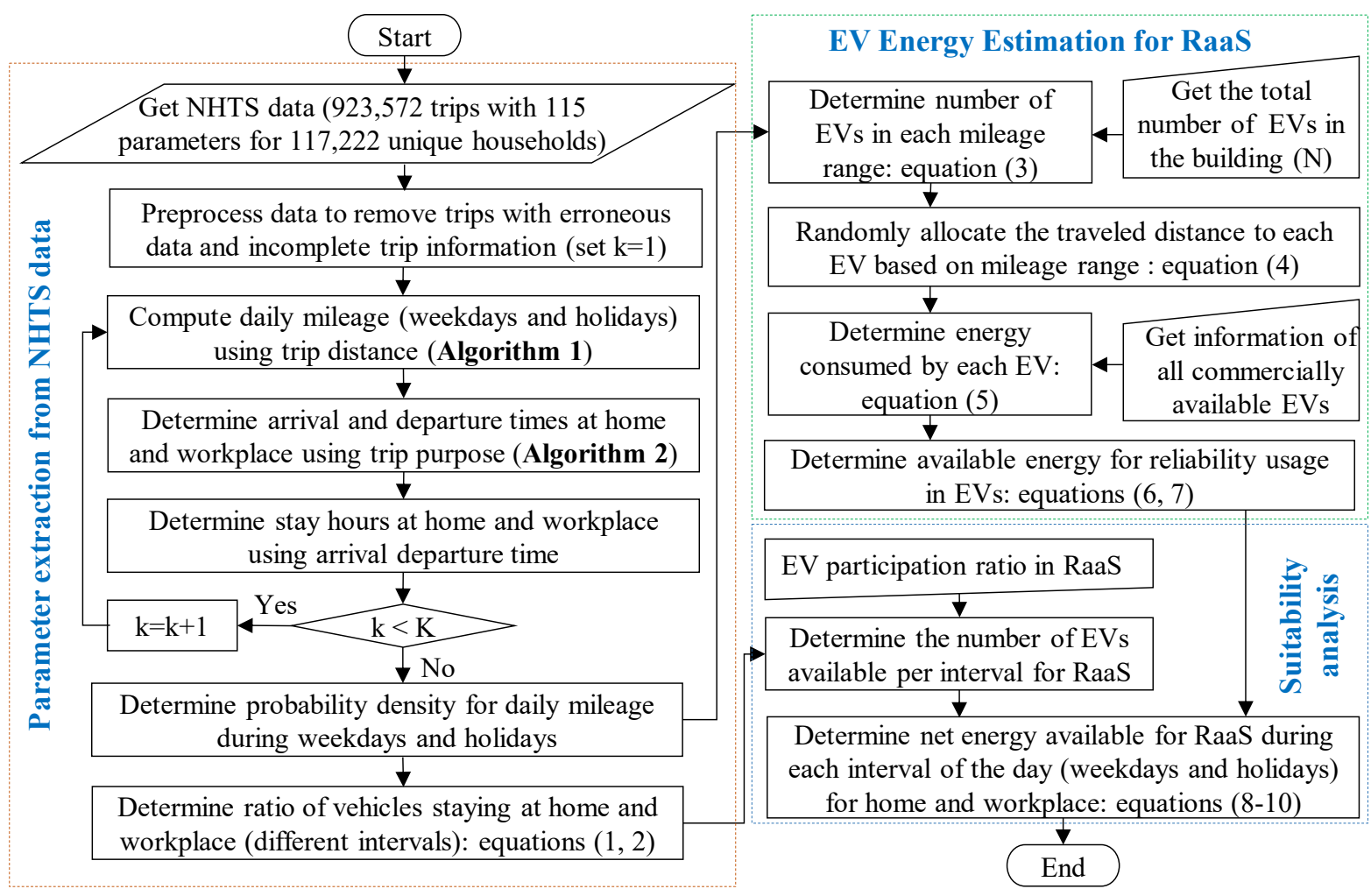

Figure 1. Flowchart for parameter extraction and suitability analysis of RaaS usage of EVs.

The step-by-step process of data extraction, EV energy estimation for proving RaaS, and suitability analysis for different building types is shown in Figure 1. This section deals with extraction of NHTS data, while the remaining two parts will be discussed in the subsequent 
sections. It is worth noting that the NHTS survey data constitute a raw dataset, which needs to be filtered first to remove erroneous entries and trips with incomplete information.

\subsection{Data Preprocessing}

The first step is to preprocess the NHTS data to remove trips with erroneous, unrealistic, and unreported data. The NHTS data provide 115 parameters per trip; details about these parameters can be found in [22]. In this study, filters are applied for only parameters of interest for this study. Some examples of filters used in this study are as follows.

- Remove trips with unreported trip mileage and/or unreported trip duration.

- Select only trips with driving mode as car, SUV, minivan, and pickup truck (remove trips on motorcycle, bicycle, school bus, public or commute bus, etc.).

- Remove trips with unidentified vehicle ID.

- Remove trips with an unspecified origin/destination and day of the trip.

- Calculate vehicle speed using reported mileage and trip duration, then remove trips with unrealistic speeds.

After applying these filters, the number of trips is reduced to 788,613 for 110,272 households with 137,382 unique vehicles. These data are used for further analysis in this study. It is worth mentioning that in this study, vehicles are tracked instead of people since one person could use different vehicles for different trips, and multiple residents of a household could use a single vehicle.

\subsection{Daily Mileage of Vehicles}

The overall process for the daily mileage computation is shown in Algorithm 1. First, the mileage of all vehicles during weekdays $\left(D_{i}^{w d d}\right)$ and holidays $\left(D_{i}^{w d}\right)$ is initialized to zero. Then, the trip counter $(k)$ and vehicle counter $(i)$ are initialized, as shown in line 2. Then, unique vehicles are identified using vehicle ID $\left(V_{k}^{i d}\right)$ and household ID $\left(H H_{k}^{i d}\right)$ fields of NHTS data, lines 3-6. After identifying a unique vehicle (i), all trips $(k)$ covered by that vehicle are tracked, and the distance covered in each trip $\left(D_{k}\right)$ is extracted from the covered-mileage field of NHTS data. Two separate variables are maintained to store the daily mileage of vehicles during weekdays $\left(D_{i}^{\text {wd }}\right)$ and holidays $\left(D_{i}^{h d}\right)$, lines 7-11. This process (lines 3-13) is repeated until all reported trips are scanned.

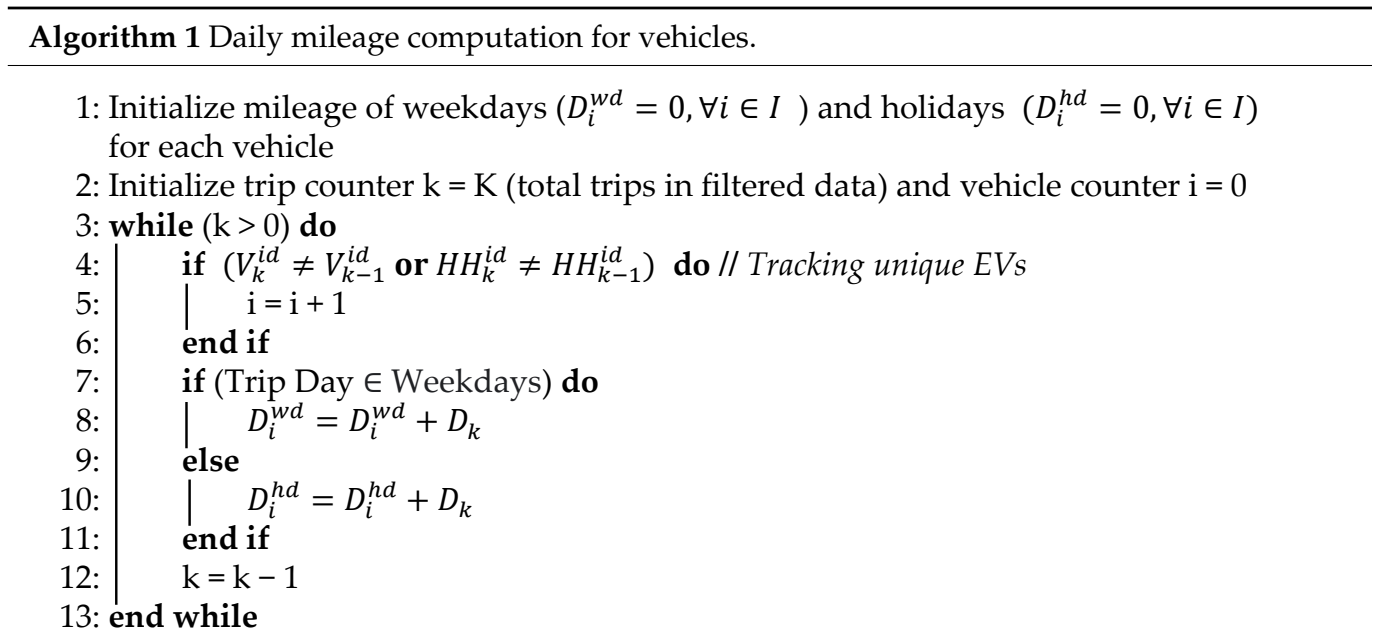

The results obtained for the daily mileage of vehicles during weekdays and holidays are shown in Figure 2. For the sake of visualization, data beyond $150 \mathrm{~km}$ is clipped in the figure. The histogram shows that the daily mileage follows a lognormal distribution, and the majority of vehicles travel less than $100 \mathrm{~km}$ a day. The overall histogram pattern is similar for both weekdays and holidays, with minute differences in some bin edges. 
These daily mileage data are later used to compute the amount of energy consumed by EVs to carry out their daily activities or to allocate energy for upcoming trips. Similarly, the travel duration of each trip is shown in the bottom part of Figure 2 for both weekdays and holidays. It can be observed that most of the trips last for less than an hour, with a higher concentration in the region of under $30 \mathrm{~min}$.

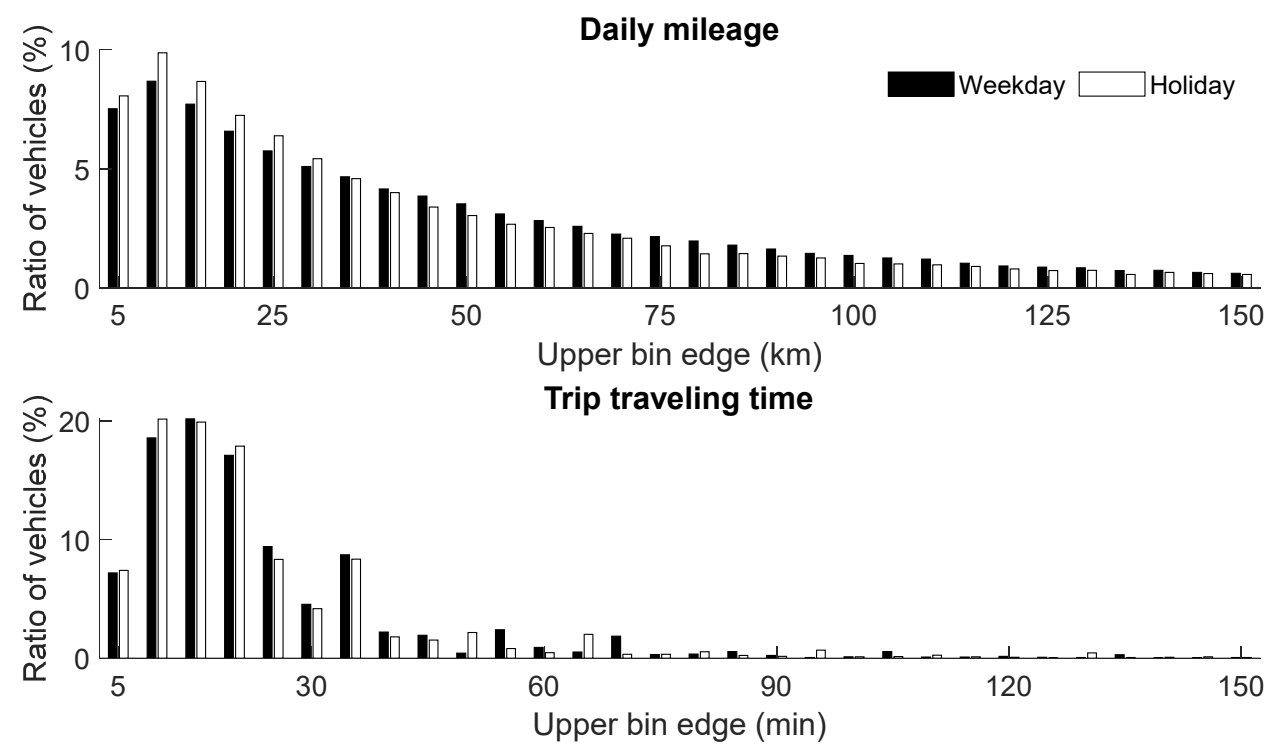

Figure 2. Daily mileage and per-trip travelling-duration histograms for vehicles.

\subsection{Daily Arrival and Departure Times}

The next step is to track the arrival and departure times of vehicles at/from home and the workplace. The overall process for tracking arrival and departure times of vehicles is shown in Algorithm 2. First, home arrival $\left(T_{i}^{\text {hax }}\right)$ and departure $\left(T_{i}^{\text {hdx }}\right)$ times for weekdays/holidays are initialized to zero for all vehicles. Then, workplace arrival $\left(T_{i}^{\text {wax }}\right)$ and departure $\left(T_{i}^{w d x}\right)$ times for weekdays/holidays are initialized to zero. Then, the trip counter $(k)$ and vehicle counter $(i)$ are initialized, as shown in line 3 . Similarly to daily mileage tracking, unique vehicles are identified first, lines 5-7. The trip day field is tracked to identify weekdays and holidays for each vehicle trip, line 8. For each working day, the trip departure-point field is tracked to identify home and workplace, lines 9,10 . The trip departure time for trip $k\left(T_{k}^{d e p}\right)$ is set to home departure time $\left(T_{i}^{h d w}\right)$ if the trip originated from home, and it is set to the workplace $\left(T_{i}^{w d w}\right)$ if it originated from the workplace. Similarly, the arrival time for each trip is tracked based on the destination point of the trip, lines 12-14. If the trip is destined for home, trip arrival time $\left(T_{k}^{a r r}\right)$ is set to home arrival time $\left(T_{i}^{\text {haw }}\right)$, and it is set to workplace arrival time ( $\left.T_{i}^{\text {wavw }}\right)$ if it was destined for the workplace. The same process is repeated for holidays, and the corresponding parameters are extracted, lines 16,17. It should be noted that the last arrival time is recorded for home, while the first arrival time is recorded for workplace arrival, i.e., in-between short trips are ignored.

The obtained results for daily arrival and departure times of vehicles during working days and holidays are shown in Figure 3. As expected, sharp peaks are observed for weekdays, while more flattened curves are observed for holidays. All these results are selfnormalized; therefore, arrival and departure time curves for the workplace during holidays can also be seen. However, the number of vehicles is significantly lower for holidays as compared to weekdays, which is discussed in the following subsection. Figure 4 shows the cumulative densities for arrival and departure times for home $(\mathrm{HO})$ and workplace (WP) during working days and holidays. Sharp rises in the cumulative density plots can be 
observed for weekdays (peak arrival and departure hours), while monotonically increasing plots can be observed for holidays.
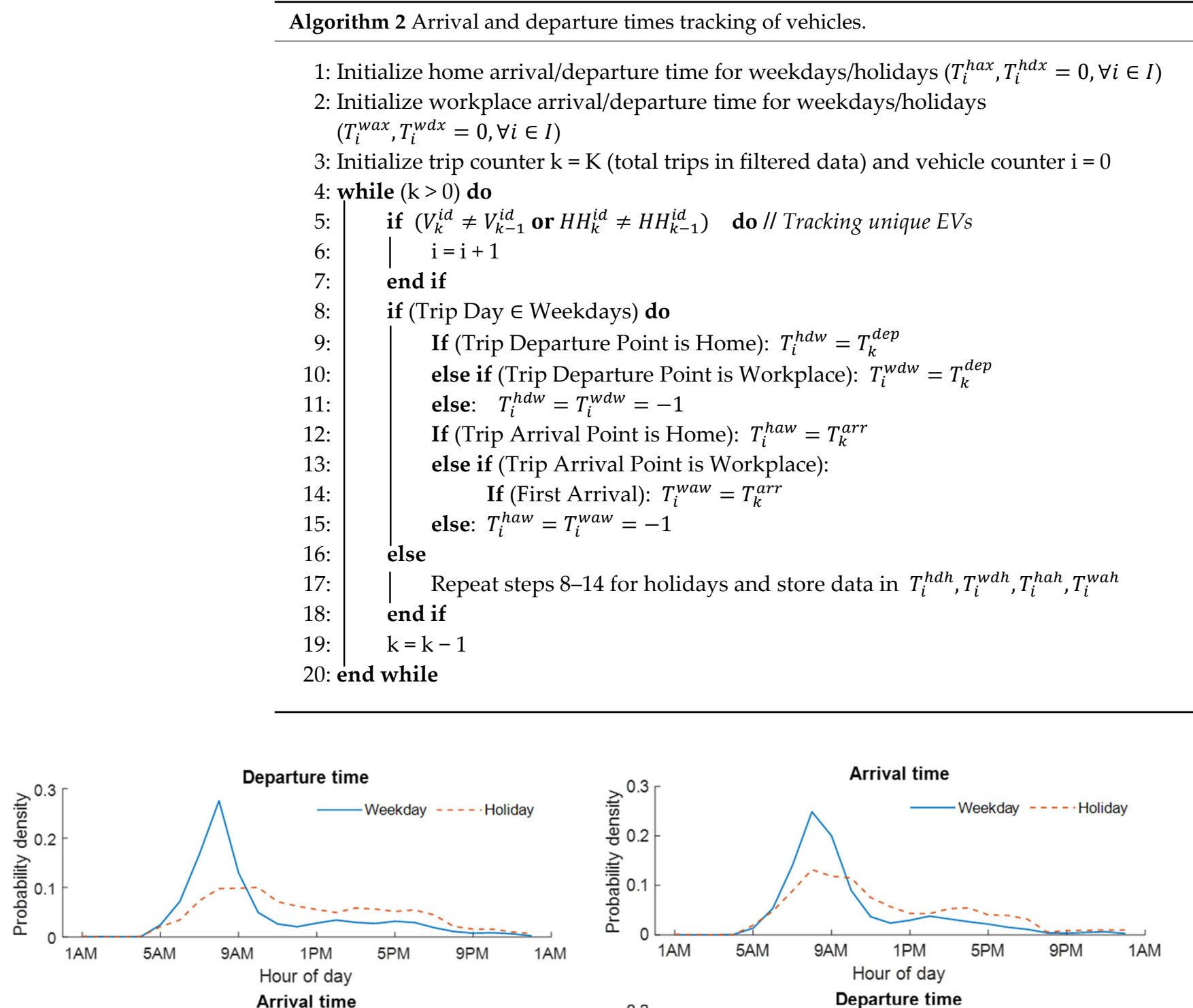

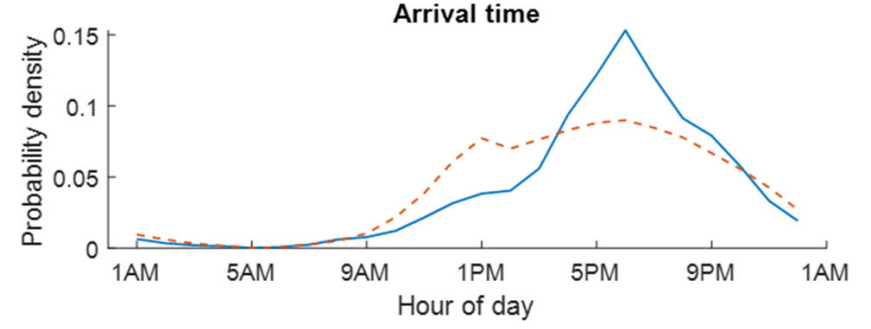

(a)

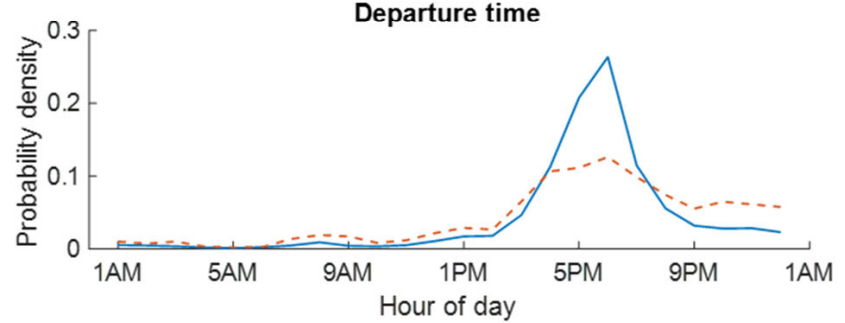

(b)

Figure 3. Probability densities of arrival and departure times: (a) home; (b) workplace. 

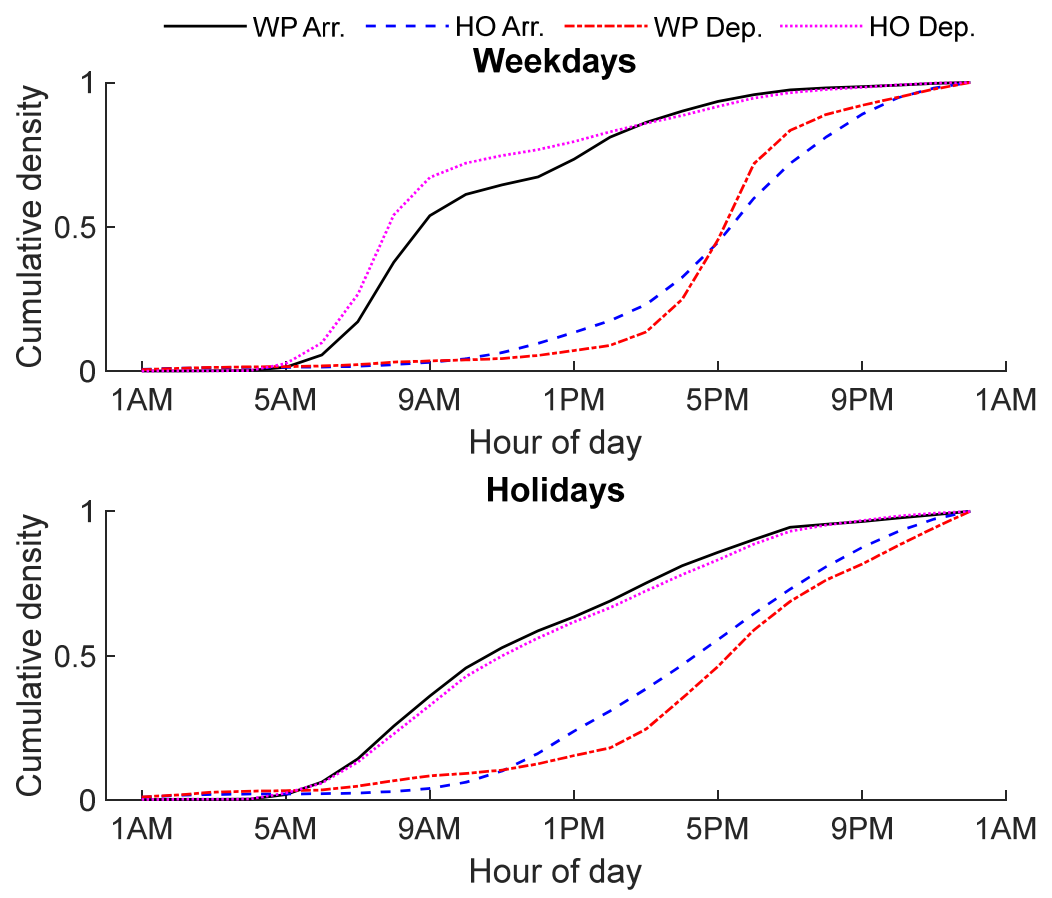

Figure 4. Cumulative densities for arrival/departure time for home/workplace.

\subsection{Vehicle Stay Time}

The percentage of vehicles staying at home is computed using the accumulated density values of arrival and departure times, shown in Figure 4. In addition, information regarding the ratio of vehicles returning to home $\left(R_{\text {ratio }}^{h}\right)$ is also required. This value is computed by tracking vehicles departing from home and then returning to home for the whole dataset and is around $96 \%$ for both weekdays and holidays. The ratio of vehicles staying at home $\left(\Gamma_{t}^{h}\right)$ can be computed using the following equation:

$$
\Gamma_{t}^{h}=R_{\text {ratio }}^{h}+\sum_{t \in[1, t]} f_{t}^{h a}-\sum_{t \in[1, t]} f_{t}^{h d} \quad \forall t \in T
$$

where $f_{t}^{h a}$ and $f_{t}^{h d}$ are the home arrival and departure probability densities, respectively, and summation is used to obtain the cumulative densities. The same process can be repeated for both working days and holidays. Similarly, the percentage of vehicles present at the workplace during different hours of the day $\left(\Gamma_{t}^{w}\right)$ can be computed as follows:

$$
\Gamma_{t}^{w}=\left(\sum_{t \in[1, t]} f_{t}^{w a}-\sum_{t \in[1, t]} f_{t}^{w d}\right) \cdot R_{\text {ratio }}^{w} \quad \forall t \in T
$$

where $f_{t}^{w a}$ and $f_{t}^{w d}$ are the workplace arrival and departure probability densities, respectively, and summation is used to obtain the cumulative densities. $R_{\text {ratio }}^{w}$ is the ratio of EVs going to work (as compared to the total number of EVs in the sample). The value of this parameter is around $58 \%$ for weekdays and $18 \%$ for holidays.

The obtained results are shown in Figure 5. It is evident that most vehicles are present at their home during late-night and early-morning hours, as expected. Similarly, a large portion of vehicles is present at the workplace during working hours. A small fraction of vehicles is present at the workplace during the holidays. This might be due to consideration of Saturdays as holidays, while some industries work Saturdays as well. In addition, some of the essential workforce still works on holidays. These results will be translated into EVs in the following section to determine the available energy of EVs to provide RaaS during different hours of the day. 


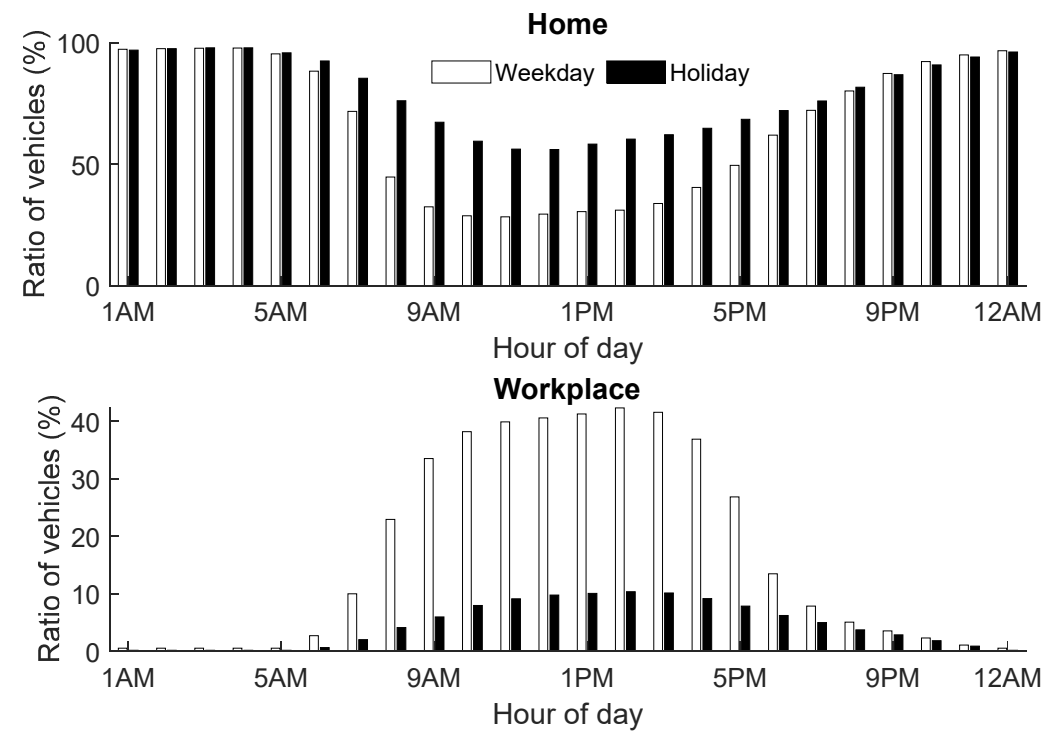

Figure 5. Percent of vehicles staying at home/workplace during different hours of day.

\section{EV Energy Estimation for RaaS}

In this section, the parameters extracted from the NHTS data are applied to EVs, and the available energy in EVs to provide RaaS during different hours of the day is analyzed. First, the useable battery size and energy consumption of all commercially available EVs are taken from [18] and are shown in Figure 6. The average usable battery size of EVs is $58.4 \mathrm{kWh}$, and the average energy consumption is $195 \mathrm{Wh} / \mathrm{km}$, as of December 2021.

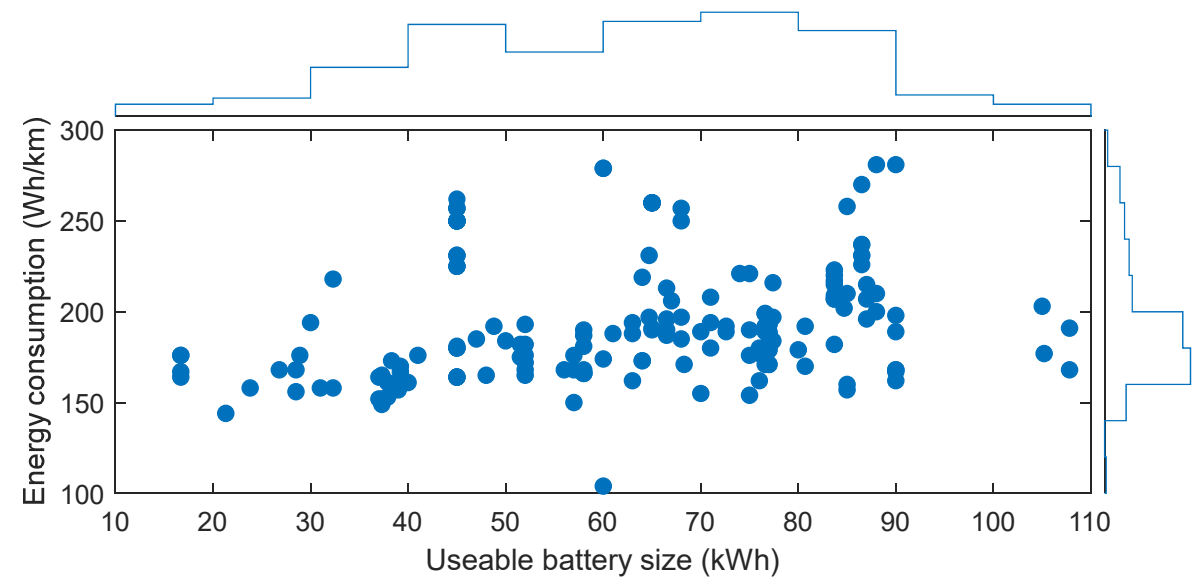

Figure 6. Energy consumption and useable battery size of commercially available EVs.

\subsection{Allocation of EVs to Different Mileage Ranges}

First, the total number of EVs $(N)$ is divided into different mileage ranges based on the mileage histogram obtained from the NHTS data, as shown in Figure 2. The number of EVs in each mileage range $\left(M_{l}\right)$ can be obtained by using the following equation:

$$
M_{l}=\operatorname{round}\left(F_{l} \cdot N\right) \forall l \in L
$$

where $F_{1}$ is the histogram value of the daily mileage for bin edge $l$. For example, if the total number of EVs is 100 , then $M_{1}, M_{2}, M_{3}$ and $M_{4}$ will be $8,9,8$, and 7, respectively. This implies that among $100 \mathrm{EVs}$, eight will travel between 1 and $5 \mathrm{~km}$, nine will travel 5 to $10 \mathrm{~km}$, eight will travel 10 to $15 \mathrm{~km}$, etc. The same process can be repeated for holidays. 
Then, the daily mileage of each EV is randomly generated within the range determined using Equation (3). The daily mileage for EVs in any bin edge, $l\left(D_{l}\right)$, is generated using the following equation:

$$
D_{l}=\operatorname{rand}\left(\left[(l-1) \cdot b^{w}, l \cdot b^{w}\right], M_{l}\right) \quad \forall l \in L
$$

where $b^{w}$ is the bin width, which is $5 \mathrm{~km}$ for weekdays and holidays. It can be observed from (4) that a vector of length $\left(M_{l}\right)$ is generated for each bin edge, $l$, within the range of $\left[(l-1) \cdot b^{w}, l \cdot b^{w}\right]$. This process is repeated for holidays to obtain the results for holiday mileages.

\subsection{Daily Energy Consumption of EVs}

After determining the daily mileage of each EV, the energy consumption of each $\mathrm{EV}$ is computed using the energy efficiency of commercially available EVs, as shown in Figure 6. Similarly to [23], it is assumed that SoC decreases linearly as a function of the traveled distance, and the energy consumption of EV $n\left(E_{n}\right)$ is computed using the following equation:

$$
E_{n}=\left(1.60934 \cdot D_{n}\right) \cdot \frac{E_{n}^{p k m}}{1000} \quad \forall n \in N
$$

where $D_{n}$ is daily mileage in miles, and $E_{n}^{p k m}$ is the energy consumption per $\mathrm{km}$ in Wh. This process is also repeated for holidays, and obtained results are shown in Figure 7. It can be observed that the daily energy consumption during both weekdays and holidays follows a lognormal distribution (approximated with red curves), similar to daily mileage. It can also be observed from the figures that around $80 \%$ of EVs consume under $20 \mathrm{kWh}$ of energy on a daily basis.
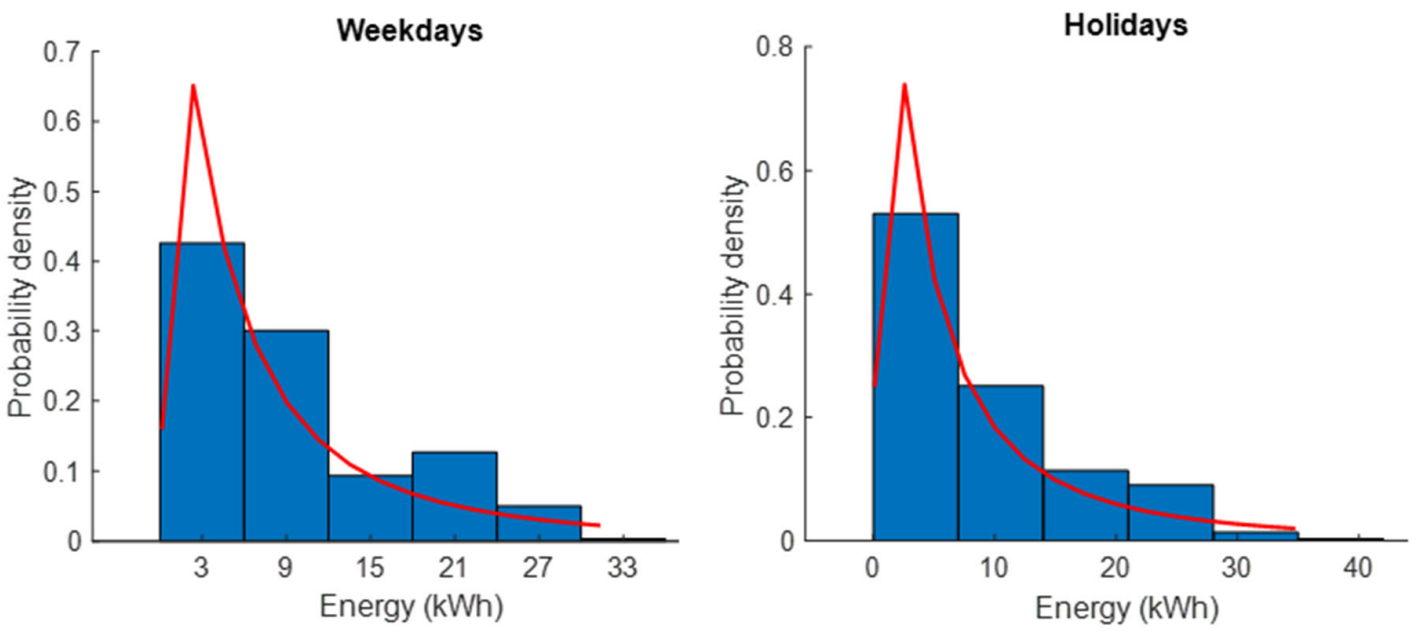

Figure 7. Daily energy consumption of EVs during weekdays and holidays.

\subsection{Energy for RaaS Usage in EVs}

After obtaining the daily mileage and energy consumption of EVs, the energy available in EVs for RaaS can be computed. To calculate the extra energy available in EVs during their stay at home $\left(E_{n}^{a h}\right)$, several parameters are required. These parameters include the energy available in the EV at the return time $\left(E_{n}^{r h}\right)$, the energy required per day $\left(E_{n}\right)$, and preferred minimum level of $\mathrm{SoC}\left(\mathrm{SoC}_{n}^{\mathrm{min}}\right)$, as given by the following equation:

$$
E_{n}^{a h}=E_{n}^{r h}-E_{n}-S o C_{n}^{\min } \cdot B_{n}^{c a p} \quad \forall n \in N
$$

where $B_{n}^{\text {cap }}$ is the capacity of the EV battery in kWh. The energy at the return time is randomly generated in the range of $[50 \%, 80 \%]$ of SoC for each EV. The same equation 
can be used for weekdays and holidays to determine the available energy. Similarly, the following equation can be used to compute the available energy in EVs at the workplace.

$$
E_{n}^{a w}=E_{n}^{r w}-\alpha_{n} \cdot E_{n}-S o C_{n}^{\min } \cdot B_{n}^{c a p} \quad \forall n \in N
$$

The parameters in Equation (7) are the same as in Equation (6), except that those in Equation (7) are for the workplace, and an additional factor $\left(\alpha_{n}\right)$ is introduced to consider the desired amount of energy to be reserved for upcoming tasks. The value of this parameter can be in the range of $[0,1]$.

Based on these formulations, the energy available in EVs during weekdays and holidays is shown in Figure 8, along with approximated normal distributions. It can be observed that most EVs can spare around $10 \mathrm{kWh}$ of energy for RaaS during both weekdays and holidays, either at home or at the workplace. It is worth mentioning that all the histograms and density functions are self-normalized. Therefore, a higher mean value at the workplace during holidays could be due to less sample data and random allocation of battery sizes and initial SoC to EVs.
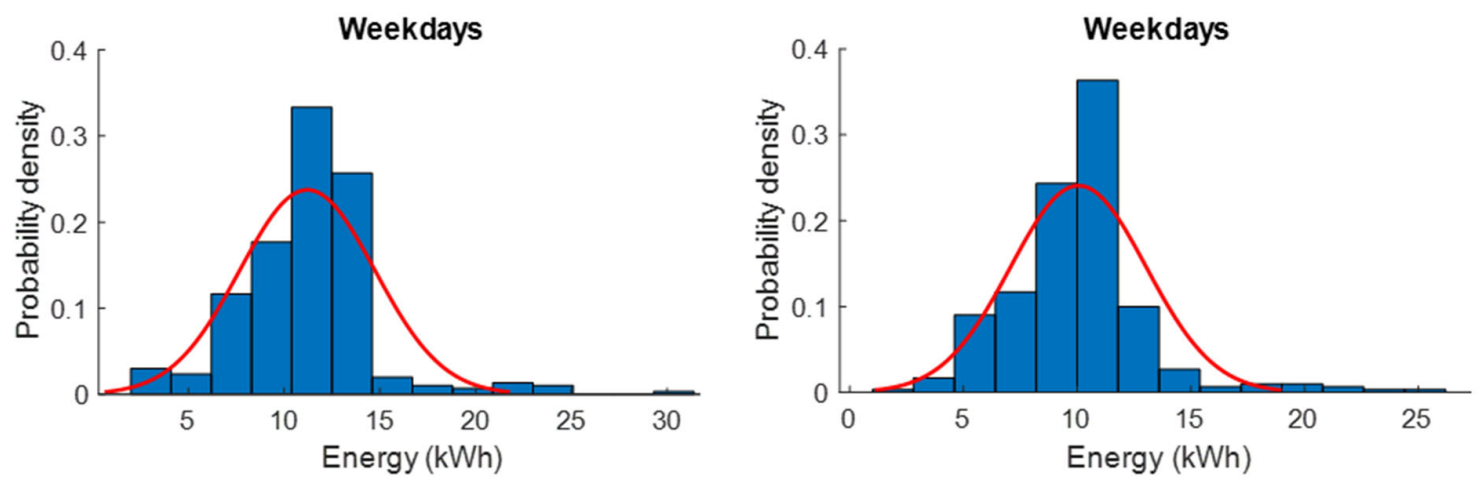

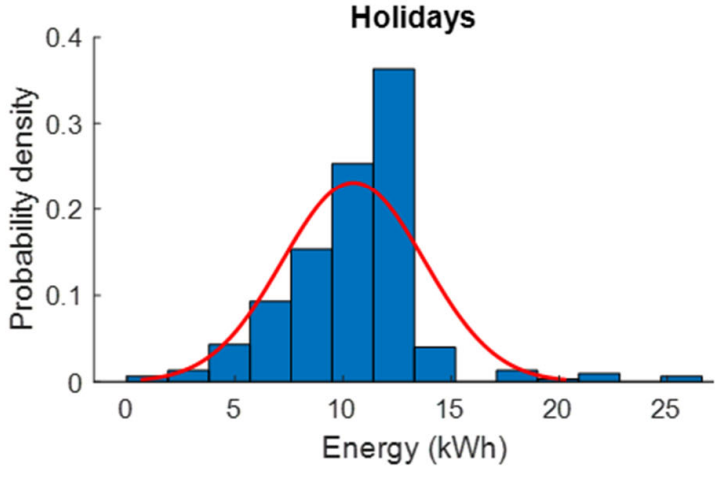

(a)

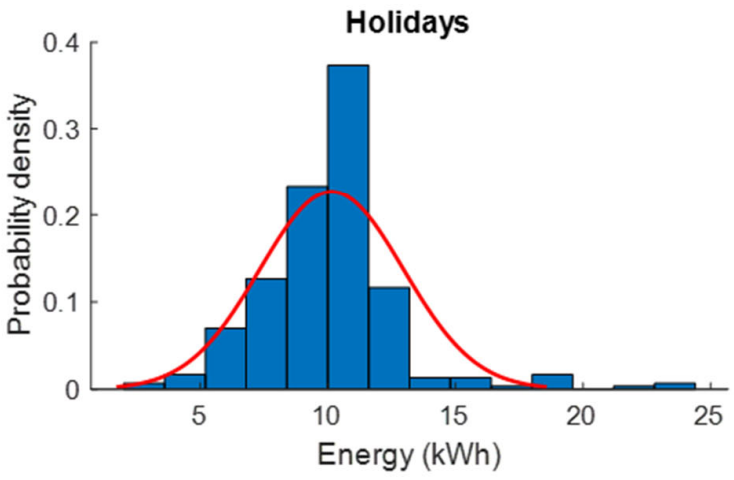

(b)

Figure 8. Useable energy for RaaS in EVs: (a) home; (b) workplace.

\section{Suitability Analysis for Different Types of Buildings}

To analyze the suitability of using EVs for RaaS, three cases are considered in this section. In the first case, residential buildings are considered, while in the second case, commercial/industrial buildings are considered. A mix of these two building types with shared parking is considered in the third case. The following equations are used to compute the amount of energy available for RaaS during the weekdays and holidays. The amount of energy available to be used for RaaS during any interval, $t\left(E_{t}^{\text {RaaS }}\right)$, can be computed using the following equation:

$$
E_{t}^{\text {RaaS }}=\sum_{n \in N}\left(\beta \cdot E_{n}^{a h}+(1-\beta) \cdot E_{n}^{a w}\right) \quad \forall t \in T
$$


where $E_{n}^{a h}$ and $E_{n}^{a w w}$ are the available amount of energy to be used for RaaS in EV $n$ at home and workplace, respectively. Coefficient $\beta$ is used to determine the ratio of home-based EVs and workplace-based EVs for mixed buildings. For residential buildings, $\beta=1$, and for commercial buildings, $\beta=0$. EVs are randomly selected from the fleet created in the previous section, as given by the following equation:

$$
n=\operatorname{rand}\left([1, N], N_{l}\right)
$$

This implies that a random sample of size $N_{t}$ is selected for each interval of the day. The size of the random sample is computed using the following equation:

$$
N_{t}=\left\{\begin{array}{c}
\operatorname{round}\left(\Gamma_{t}^{h} \cdot N \cdot \beta \cdot \gamma^{\text {RaaS }}\right) \quad \forall t \in T \\
\operatorname{round}\left(\Gamma_{t}^{w} \cdot N \cdot(1-\beta) \cdot \gamma^{\text {RaaS }}\right) \quad \forall T \in T
\end{array}\right.
$$

where $\gamma^{\text {RaaS }}$ is the ratio of EVs willing to participate in the RaaS, which can take any value in the range of $[0,1] . \Gamma_{t}^{h}$ and $\Gamma_{t}^{w}$ are the ratio of vehicles staying at home and workplace, respectively, as given by Equations (1) and (2).

The focus of this study is on analyzing the suitability of EVs to provide RaaS in multiunit residential buildings/apartments and workplaces, where several residents/workers share a common parking space. Therefore, in this section, a fleet of $25 \mathrm{EVs}$ is analyzed. Sensitivity analysis for different EV fleets is presented in the next section.

\subsection{Residential Buildings}

In this section, only multi-unit residential buildings are considered, and different participation ratios of EVs are analyzed. For each case, the amount of energy available for RaaS during different hours of the day is analyzed. The participation ratio is varied between 10 and $90 \%$, and nine cases are simulated. In each case, the simulation is repeated 500 times by randomly allocating EVs. The average values of 500 runs are shown in the following figures to provide a generalized picture.

It can be observed from Figures 9 and 10 that with an increase in the participation ratio, available energy also increases, as expected. However, the amount of energy available for different hours of the day is not uniform. For the sake of visualization, the $50 \%$ participation case is shown separately in Figure 11. It can be observed that during weekdays, useable energy reduces to a mean of about $60 \mathrm{kWh}$ for the late morning and early evening hours, when a large portion of EV owners is at work. However, the mean energy during the same hours is about $110 \mathrm{kWh}$ for weekends due to the larger number of EV owners staying at home. Nevertheless, a similar average energy value is available for late-night and late-evening hours for both weekdays and holidays. It can be concluded that for a $50 \%$ participation of EV owners with 25 home-based EVs, an average of about $60 \mathrm{kWh}$ of backup power can be provided, irrespective of the day type and hour of the day. This is the minimum level of energy that can be provided (corresponding to working days, working hours). During all other intervals, a greater amount of backup can be provided. The lowest value will be the bottleneck and hence the maximum level of backup that can be secured.

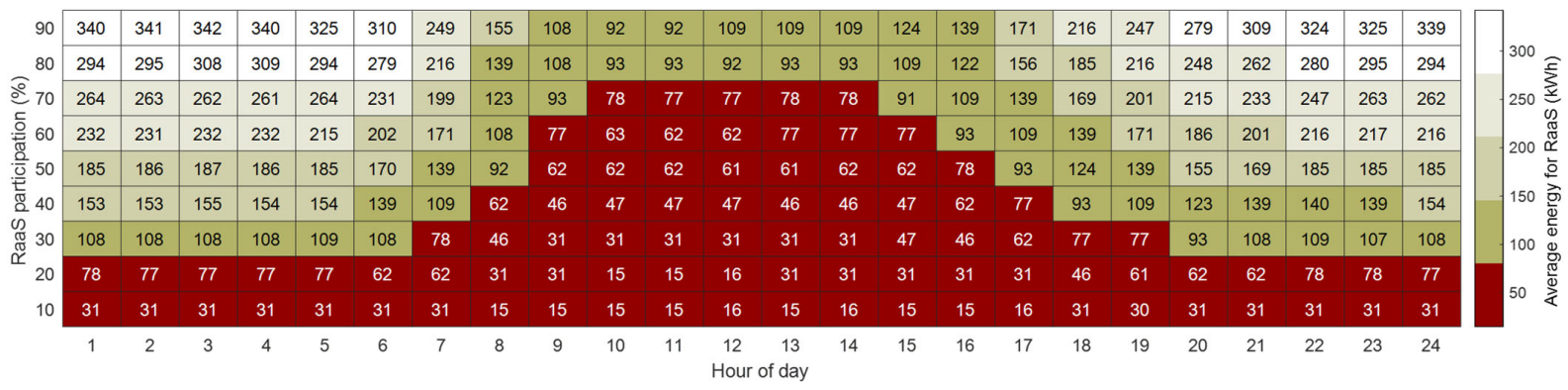

Figure 9. Results of useable energy in residential buildings for RaaS during weekdays. 


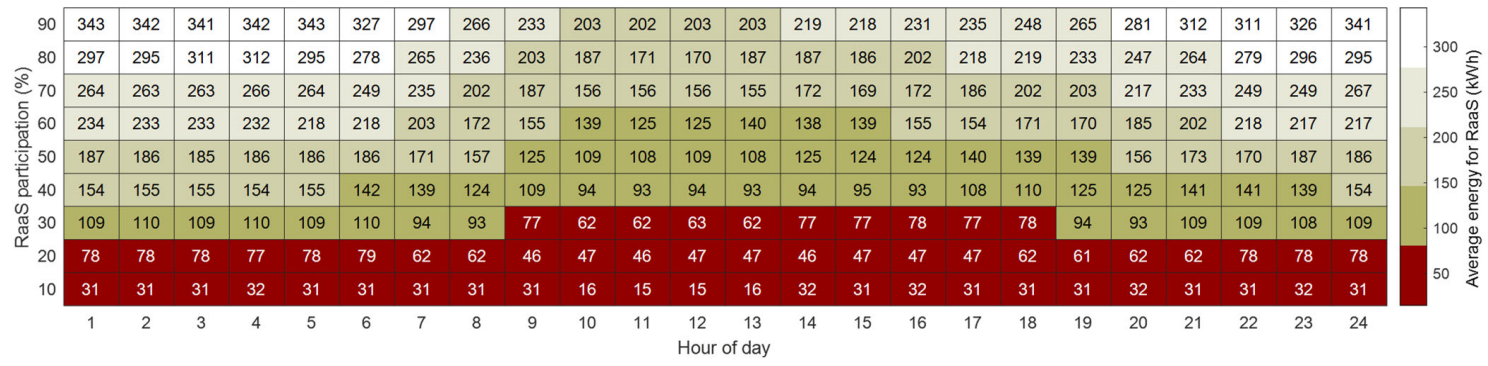

Figure 10. Results of useable energy in residential buildings for RaaS during holidays.

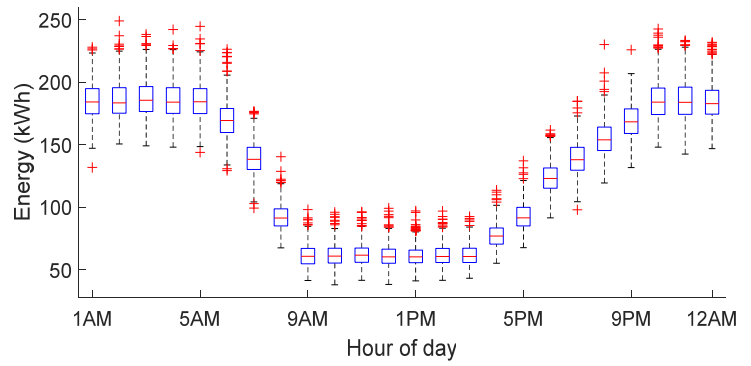

(a)

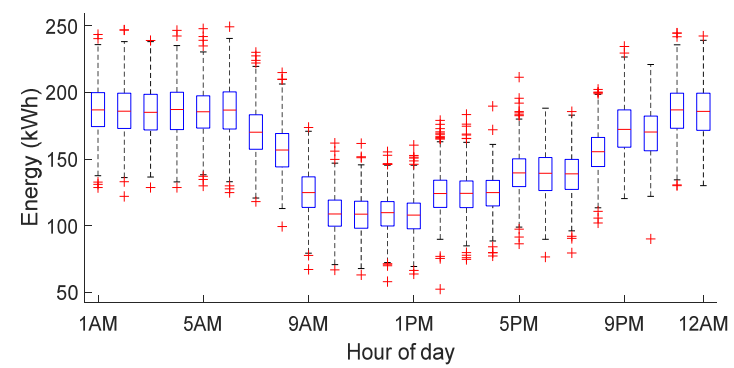

(b)

Figure 11. Useable energy in resintial buildings for 50\% participation case: (a) weekdays; (b) holidays.

\subsection{Commercial/Industrial Buildings}

Similarly to the residential case, the participation ratio of EV owners is varied between 10 and $90 \%$, and nine cases are simulated for commercial/industrial buildings in this section. Similarly to the previous section, each case is repeated 500 times, and the average results are shown in Figures 12 and 13. It can be observed that during early-morning and late-night hours, none of the EVs is at the workplace. Therefore, the useable energy amount is zero during these intervals, for both weekdays and holidays. However, during working hours, the amount of useable energy increases with an increase in the participation ratio. For the sake of visualization, the $50 \%$ penetration case is shown in Figure 14 for weekdays and holidays.

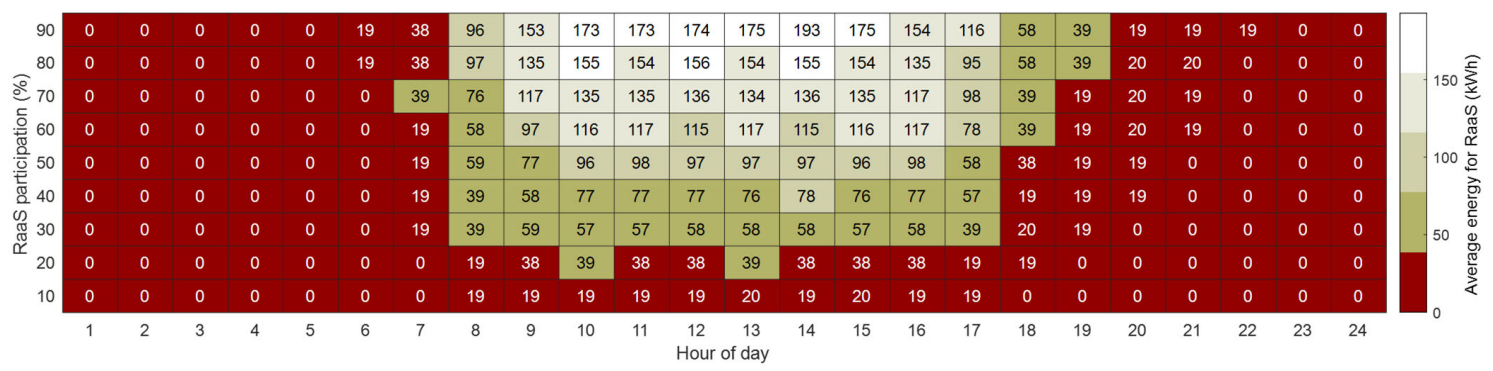

Figure 12. Results of useable energy in commercial/industrail buildings for RaaS during weekdays.

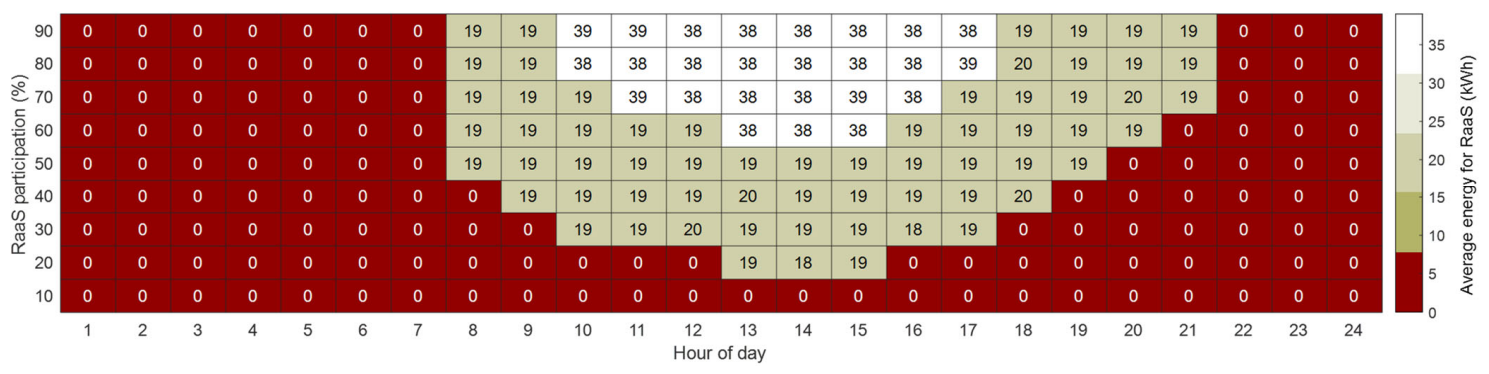

Figure 13. Results of useable energy in commercial/industrial buildings for RaaS during holidays. 


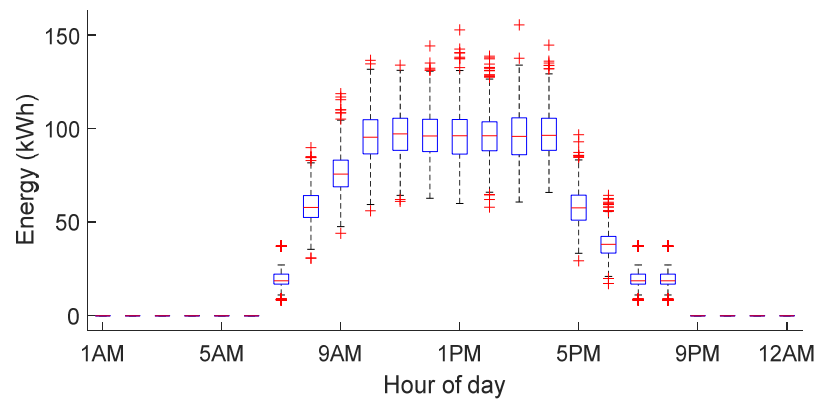

(a)

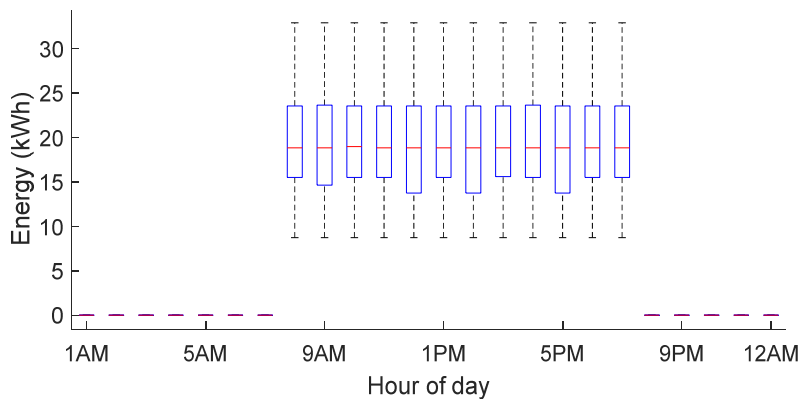

(b)

Figure 14. Useable energy in commercial/industrial buildings for $50 \%$ participation case: (a) weekdays; (b) holidays.

It can be observed from Figure 14 that during non-office hours, none of the EVs is present in the parking lot, and thus, no energy can be used for both weekdays and holidays. However, it is interesting to note that the maximum amount of energy available for RaaS at the workplace with a $50 \%$ participation ratio is about $100 \mathrm{kWh}$, which is significantly less than that available for residential buildings. This is because the ratio of vehicle owners going to work is about 58\%; thus, the total number of EVs at the workplace is 15 instead of 25. Similarly, a very minute amount of energy can be provided as a backup during weekends, as depicted in Figure 14. It can be concluded from this analysis that EVs are not suitable to provide RaaS to commercial/industrial-only buildings. With EVs, it is difficult to secure any amount of energy for RaaS in these buildings. For example, during early-morning and late-night hours, none of the EVs is at the workplace, and thus, no energy is available for RaaS. In addition, there is a significant difference in the amount of energy available for RaaS between weekdays and holidays, even during the daytime.

\subsection{Mixed Buildings}

In this section, an analysis of mixed buildings is carried out, where the parking area is shared by both residential and commercial/industrial buildings. Similarly to the previous cases, a total of $25 \mathrm{EVs}$ are considered in this section, which corresponds to $15 \mathrm{EVs}$ in the workplace. The $50 \%$ participation case is considered in this section, and the ratio of home-based EVs $(\beta)$ is varied between 5 and $50 \%$, and 10 cases are tested. Therefore, the ratio of workplace EVs will be between 50 and 95\%, (1- $\beta$ ) in Equation (10). Simulations for each case are run 500 times, and average results are shown in Figures 15 and 16.

\begin{tabular}{|c|c|c|c|c|c|c|c|c|c|c|c|c|c|c|c|c|c|c|c|c|c|c|c|c|c|}
\hline 50 & 115 & 116 & 116 & 116 & 116 & 116 & 98 & 79 & 80 & 80 & 80 & 101 & 101 & 101 & 102 & 100 & 100 & 99 & 97 & 97 & 97 & 115 & 116 & 116 & \multirow{2}{*}{-110} \\
\hline \multirow{8}{*}{ 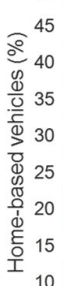 } & 97 & 97 & 97 & 97 & 97 & 97 & 97 & 99 & 80 & 101 & 101 & 101 & 101 & 101 & 101 & 101 & 99 & 79 & 99 & 96 & 96 & 97 & 96 & 97 & \\
\hline & 97 & 96 & 96 & 97 & 97 & 78 & 98 & 80 & 102 & 82 & 81 & 82 & 101 & 102 & 101 & 102 & 80 & 79 & 98 & 77 & 77 & 96 & 97 & 96 & \\
\hline & 77 & 78 & 76 & 78 & 77 & 77 & 79 & 80 & 81 & 83 & 81 & 82 & 82 & 83 & 82 & 101 & 80 & 79 & 79 & 77 & 77 & 78 & 78 & 78 & \\
\hline & 77 & 77 & 77 & 77 & 77 & 58 & 78 & 80 & 81 & 81 & 82 & 102 & 103 & 102 & 103 & 102 & 81 & 59 & 78 & 58 & 58 & 58 & 77 & 77 & \\
\hline & 58 & 58 & 58 & 58 & 58 & 58 & 59 & 61 & 81 & 103 & 103 & 102 & 103 & 102 & 103 & 82 & 101 & 60 & 59 & 58 & 58 & 58 & 58 & 58 & \\
\hline & 38 & 38 & 38 & 39 & 39 & 39 & 60 & 61 & 82 & 103 & 102 & 102 & 103 & 103 & 103 & 102 & 81 & 60 & 59 & 59 & 38 & 39 & 39 & 38 & \\
\hline & 39 & 39 & 39 & 39 & 39 & 38 & 39 & 61 & 101 & 102 & 102 & 102 & 101 & 102 & 101 & 102 & 82 & 40 & 40 & 59 & 39 & 39 & 38 & 39 & \\
\hline & 19 & 19 & 19 & 19 & 19 & 19 & 40 & 81 & 84 & 83 & 82 & 105 & 104 & 104 & 104 & 103 & 83 & 61 & 40 & 40 & 19 & 19 & 20 & 20 & \\
\hline 5 & 19 & 19 & 19 & 19 & 20 & 19 & 21 & 63 & 83 & 105 & 104 & 104 & 105 & 105 & 104 & 83 & 62 & 41 & 21 & 40 & 19 & 19 & 19 & 19 & \\
\hline & 1 & 2 & 3 & 4 & 5 & 6 & 7 & 8 & 9 & 10 & 11 & $\begin{array}{c}12 \\
\text { Hour }\end{array}$ & $\begin{array}{l}13 \\
\text { d day }\end{array}$ & 14 & 15 & 16 & 17 & 18 & 19 & 20 & 21 & 22 & 23 & 24 & \\
\hline
\end{tabular}

Figure 15. Results of useable energy in mixed buildings for RaaS during weekdays. 


\begin{tabular}{|c|c|c|c|c|c|c|c|c|c|c|c|c|c|c|c|c|c|c|c|c|c|c|c|c|c|}
\hline \multirow{8}{*}{ 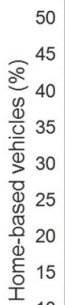 } & 110 & 111 & 112 & 112 & 111 & 111 & 93 & 93 & 74 & 74 & 95 & 94 & 95 & 95 & 94 & 94 & 74 & 75 & 94 & 93 & 92 & 110 & 110 & 112 & \multirow{3}{*}{$\int_{80}^{100}$} \\
\hline & 92 & 92 & 94 & 111 & 93 & 93 & 93 & 73 & 74 & 75 & 75 & 75 & 76 & 76 & 76 & 94 & 94 & 74 & 74 & 92 & 92 & 93 & 92 & 93 & \\
\hline & 92 & 93 & 94 & 93 & 92 & 93 & 75 & 74 & 56 & 75 & 76 & 76 & 76 & 77 & 76 & 76 & 76 & 74 & 74 & 74 & 75 & 93 & 92 & 93 & \\
\hline & 75 & 74 & 75 & 74 & 75 & 74 & 73 & 56 & 56 & 75 & 57 & 57 & 76 & 76 & 75 & 76 & 76 & 76 & 56 & 74 & 74 & 75 & 75 & 74 & \\
\hline & 74 & 74 & 74 & 73 & 74 & 55 & 56 & 56 & 77 & 57 & 58 & 57 & 57 & 57 & 57 & 57 & 76 & 75 & 56 & 55 & 56 & 56 & 74 & 73 & \\
\hline & 56 & 55 & 56 & 55 & 56 & 56 & 56 & 36 & 57 & 57 & 58 & 57 & 57 & 57 & 57 & 58 & 58 & 57 & 37 & 55 & 56 & 55 & 56 & 55 & \\
\hline & 38 & 37 & 37 & 38 & 37 & 37 & 37 & 37 & 57 & 39 & 39 & 39 & 39 & 58 & 57 & 57 & 58 & 57 & 37 & 37 & 37 & 37 & 37 & 37 & \\
\hline & 36 & 38 & 36 & 37 & 37 & 37 & 37 & 19 & 39 & 39 & 39 & 39 & 39 & 39 & 39 & 39 & 39 & 39 & 39 & 37 & 37 & 37 & 37 & 37 & \\
\hline$\perp_{10}$ & 18 & 18 & 18 & 18 & 19 & 19 & 18 & 19 & 39 & 39 & 38 & 39 & 38 & 39 & 38 & 38 & 39 & 39 & 38 & 19 & 18 & 19 & 19 & 19 & \\
\hline 5 & 19 & 18 & 19 & 18 & 18 & 19 & 19 & 0 & 20 & 20 & 20 & 20 & 20 & 20 & 20 & 20 & 20 & 20 & 20 & 19 & 18 & 18 & 18 & 19 & \\
\hline & 1 & 2 & 3 & 4 & 5 & 6 & 7 & 8 & 9 & 10 & 11 & $\begin{array}{c}12 \\
\text { Hour }\end{array}$ & $\begin{array}{c}13 \\
\text { f day }\end{array}$ & 14 & 15 & 16 & 17 & 18 & 19 & 20 & 21 & 22 & 23 & 24 & \\
\hline
\end{tabular}

Figure 16. Results of useable energy in mixed buildings for RaaS during holidays.

It can be observed that the amount of energy that can be used during the earlymorning and late-night hours increases with an increase in the value of $\beta$. However, there is no significant difference during working hours on weekdays. It is worth noting that the difference in the amount of useable energy across different hours of the day is less significant as compared to the previous two cases (residential-only and commercial/industrial-only buildings). This is due to the presence of more EVs in residential areas during nighttime and the presence of more EVs in the workplace during daytime. Therefore, shared parking lots have a higher probability of having EVs present at all times. In particular, the difference is minimal when the value of $\beta$ is between 35 and $45 \%$.

For the sake of visualization, the $35 \%$ case is shown in Figure 17. It can be observed that the fluctuations in the amount of average available energy for RaaS are significantly reduced at different times of the day. Fluctuations are visible only during traveling intervals, i.e., when vehicles are neither at home nor at workplace. It is interesting to note that this is true for both weekdays and holidays. Although during holidays, the number of EVs in the workplace is significantly lower, the number of EVs at home is higher compared to working days. Therefore, the net effect is the same for all days. It can be concluded that for mixed buildings, with $35 \%$ home-based EVs, $60 \mathrm{kWh}$ of energy can be provided for RaaS, regardless of the type of day and the hour of the day. This assurance of a certain amount of energy is important for building planners in planning backup power for buildings. Therefore, it can be concluded that mixed buildings are best suited for using EVs to provide RaaS.

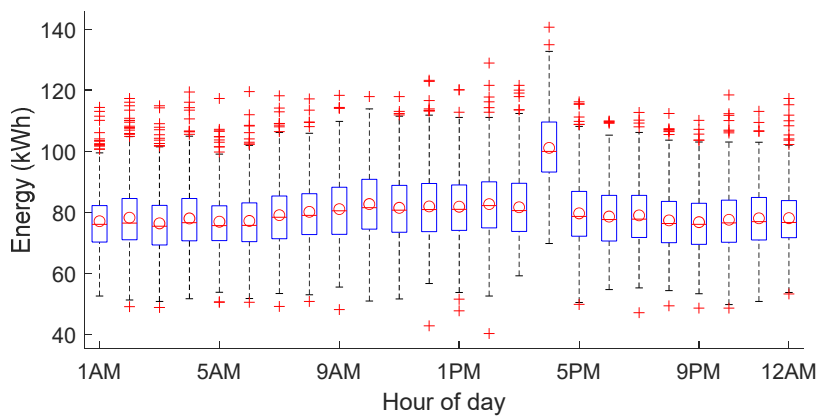

(a)

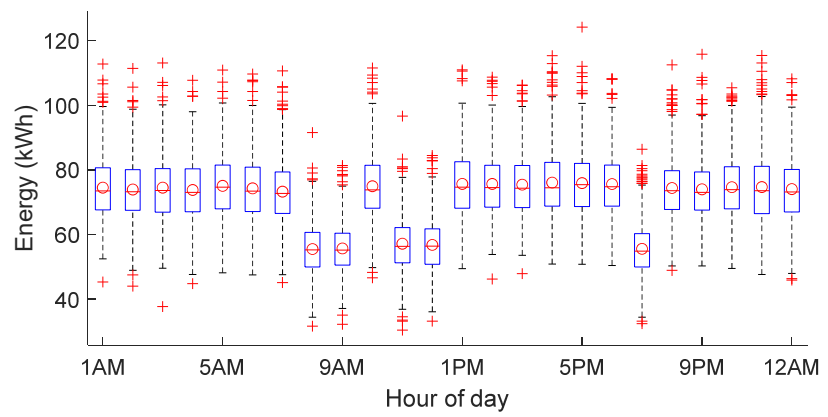

(b)

Figure 17. Useable energy in mixed buildings for $50 \%$ participation with $35 \%$ home-based EVs case: (a) weekdays; (b) holidays.

\section{Discussion and Analysis}

\subsection{Variation Index for Mixed Buildings}

It was demonstrated in the previous section that mixed buildings are suitable for using EVs in the provision of RaaS. However, the main concern of policy makers is to determine the number of EVs to be contracted to ensure a certain amount of backup power throughout the year. In addition, the ratio of EVs from the residential and commercial/industrial sectors 
is also of interest in the case of mixed buildings. Therefore, an index is proposed in this study to analyze the desired ratio of home-based and work-based EVs. The proposed variation index $\left(V_{\beta}\right)$ shows the variation in the values across different hours of the day. It can be computed using the following equation:

$$
V_{\beta}=\frac{\left(E_{\beta, \text { max }}^{\text {RaaS }}-E_{\beta, \text { min }}^{\text {RaaS }}\right)}{\left(\mu_{\beta}^{\text {RaaS }}-\sigma_{\beta}^{\text {RaaS }}\right)} \quad \forall t \in T
$$

where $E_{\beta, \max }^{\text {Raa }}$ and $E_{\beta, \min }^{\text {RaaS }}$ are the maximum and minimum amount of energy, respectively, for each case, and $\beta$ is the ratio of home-based EVs. Similarly, $\mu_{\beta}^{\text {RaaS }}$ and $\sigma_{\beta}^{\text {RaaS }}$ are the mean and standard deviation, respectively, of the energy for each case. The proposed index shows the difference in the amount of energy available for RaaS under a given EV fleet size. Lower values are desirable since they correspond to lesser variations in the available energy for RaaS. In this section, each simulation is run 1000 times, and means of those values are used for each interval.

It can be observed from Figure 18 that the variation index is lowest when the ratio of home-based EVs is between 30 and 50\% in all cases. Although the index is lower for other ratios in the case of holidays, it is not simultaneously lower for weekdays. Therefore, the ratios where the index is simultaneously lower for both weekdays and holidays are considered suitable ratios.
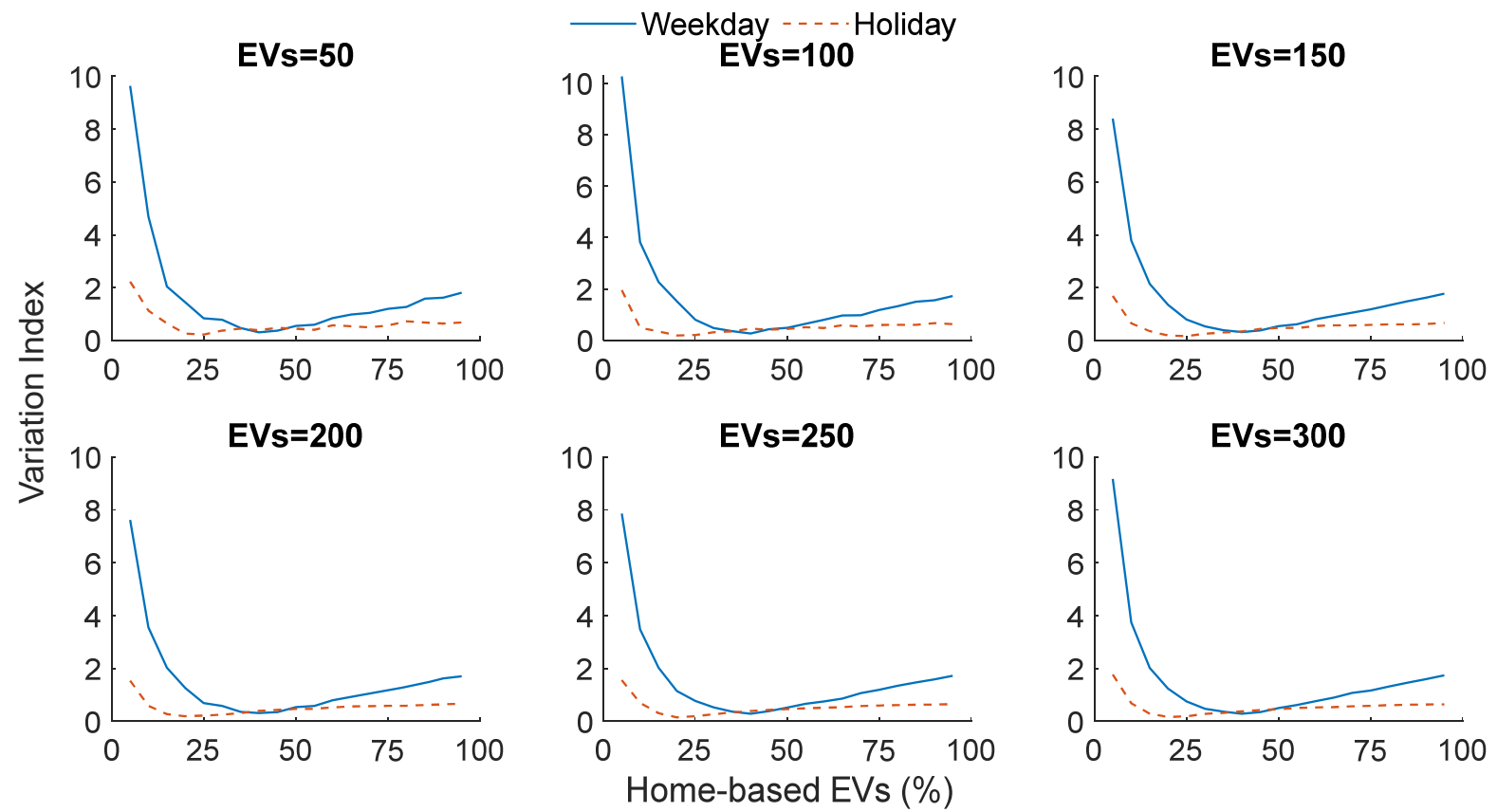

Figure 18. Variation index for different EV fleet sizes.

\subsection{EV Fleet Size and Available Energy for RaaS}

The amount of energy available for RaaS in any building is directly proportional to the size of the EV fleet. However, the daily energy consumption and the useable battery size of different EVs are not the same. Similarly, the desired minimum SoC level and the energy required for upcoming trips are also different for different EV owners. Therefore, in this section, the size of the EV fleet is varied between 50 and 300, with a step size of 50, and six cases are simulated. The simulation is repeated 1000 times in each case to visualize the upper and lower bounds of available energy for RaaS.

The available energy for RaaS with this mixed building configuration under different EV fleet sizes is shown in Figure 19. It can be observed that available energy increases 
with the EV fleet size, as expected. However, this relationship is not linear throughout the analyzed horizon, which is due to different uncertainties, as discussed in the previous paragraph. In addition, the SoC level and size of EV battery selected for each run are also different due to random selection. It can be concluded from this analysis $(50 \%$ participation with $35 \%$ home-based EVs) that about $6 \mathrm{kWh}$ of energy can be used per participating EV for RaaS.

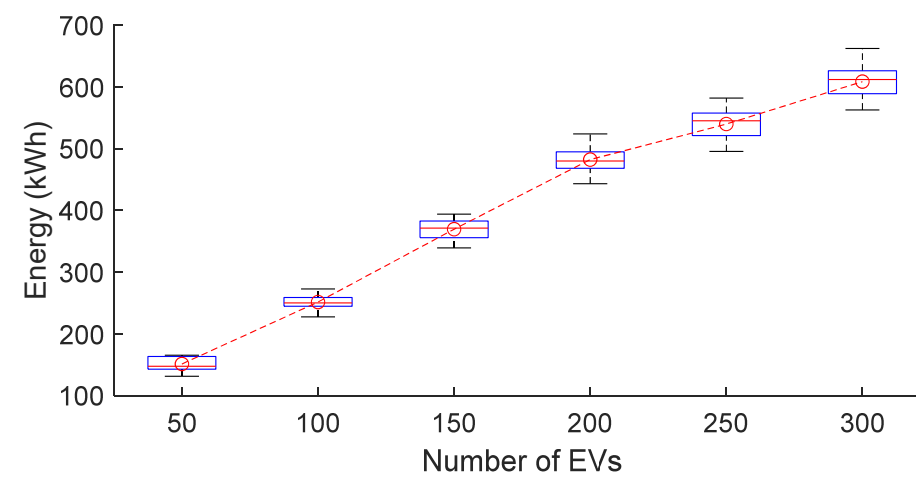

Figure 19. Available energy for RaaS under different EV fleet sizes.

\subsection{Future Research Directions}

Based on the results obtained in this study, further analysis can be carried out to evaluate the useability of EVs to provide RaaS, considering the load characteristics of different buildings. In addition, the presence of EVs in a location (e.g., apartment, school, shopping mall, university, etc.) correlates with the presence of humans, which implies that a greater amount of energy will be required during outages and vice-versa. Therefore, the potential future research directions can be summarized as follows:

- Estimation of optimum EV fleet sizes for different building types, considering the load characteristics, such as load nature (critical vs. non-critical) and magnitude of loads (required duration of backup power).

- Determination of the potential of using EVs for a particular type of commercial/industrial building, considering the correlation between the presence of EVs and the amount of critical load.

- Analysis of the potential of using EVs to provide RaaS to industrial buildings located in the suburbs with poor public transportation systems. This will change the ratio of vehicles used for commuting and, consequently, the amount of energy available for RaaS.

\section{Conclusions}

In this study, the suitability of using electric vehicles to provide reliability-as-a-service for different buildings is analyzed. A large set of driver behavior data is analyzed to extract relevant parameters, and parameters of electric vehicles are extracted from the database of commercially available electric vehicles. Suitability analysis is carried out for buildings that have residential, workplace, and shared parking places. The analysis shows that only commercial/industrial buildings are not suitable to provide reliability-as-a-service during power outages. However, mixed buildings (residential and commercial/industrial) with shared parking spaces are the most suitable building type for using electric vehicles to serve as a backup power source. It is also observed that $30-50 \%$ of home-based electric vehicles and the remaining workplace-based vehicles is the desired ratio. These ratios can provide minimum variations in the available energy during different hours of the day for both weekdays and holidays. Finally, it has been shown that each registered electric vehicle can provide about $6 \mathrm{kWh}$ of energy per day towards the backup power pool.

Author Contributions: Conceptualization, A.H. and P.M.; methodology, A.H.; validation, A.H.; writing-original draft preparation, A.H.; writing-review and editing, P.M.; supervision, P.M.; project administration, P.M. All authors have read and agreed to the published version of the manuscript. 
Funding: This research has been supported by the Natural Sciences and Engineering Research Council (NSERC) of Canada, grant number ALLRP 549804-19, and by the Alberta Electric System Operator (AESO), AltaLink, ATCO Electric, ENMAX, EPCOR Inc., and FortisAlberta.

Institutional Review Board Statement: Not applicable.

Informed Consent Statement: Not applicable.

Data Availability Statement: Not applicable.

Conflicts of Interest: The authors declare no conflict of interest.

\section{Nomenclature}

\begin{tabular}{|c|c|}
\hline \multicolumn{2}{|l|}{ Abbreviations } \\
\hline BESS & Battery energy storage system \\
\hline EV & Electric vehicle \\
\hline NHTS & National Household Travel Survey \\
\hline RaaS & Reliability-as-a-service \\
\hline SoC & State-of-charge \\
\hline \multicolumn{2}{|l|}{ Identifiers } \\
\hline$i$ & Identifier for unique vehicles, running from 1 to $I$. \\
\hline$k$ & Identifier for unique trips, running from 1 to $K$. \\
\hline$t$ & Identifier for interval of a day, running from 1 to $T$ (24). \\
\hline$l$ & Identifier for number of bin edges (used in daily mileage), running from 1 to $L$. \\
\hline$n$ & Identifier for EVs, running from 1 to $N$. \\
\hline \multicolumn{2}{|c|}{ Parameters and variables } \\
\hline$D_{i}^{w d}, D_{i}^{h d}$ & Daily mileage of vehicle, $i$, for weekdays and holidays, respectively. \\
\hline$V_{k}^{i d}$ & Identity of vehicle used for trip $k$. \\
\hline$\hat{H} H_{k}^{i d}$ & Identity of the household from where trip $k$ was carried out. \\
\hline$D_{k}$ & Distance traveled in miles during trip $k$. \\
\hline$T_{i}^{h a x}, T_{i}^{h d x}$ & Home arrival and departure time, respectively, $x \in\{\mathrm{w}$ : weekdays, $\mathrm{h}$ : holidays $\}$. \\
\hline$T_{i}^{w a x}, T_{i}^{w d x}$ & Workplace arrival and departure time, respectively, $x \in\{\mathrm{w}$ : weekdays, h: holidays $\}$ \\
\hline$T_{k}^{a r r}, T_{k}^{d e p}$ & Arrival and departure time, respectively for trip $k$. \\
\hline$\Gamma_{t}^{\tilde{h}}, \Gamma_{t}^{w}$ & The ratio of vehicles staying at home and workplace, respectively, during time $t$. \\
\hline$R_{\text {ratio, }}^{h} R_{\text {ratio }}^{w}$ & The ratio of vehicles returning home and used for commute, respectively. \\
\hline$f_{t}^{h a}, f_{t}^{h d}$ & Home arrival and departure probability density, respectively, for time $t$. \\
\hline$f_{t}^{w a}, f_{t}^{w d}$ & Workplace arrival and departure probability density, respectively, for time $t$. \\
\hline$F_{1}$ & Histogram value of the daily mileage for bin edge $l$. \\
\hline$M_{l}$ & Number of EVs in mileage range corresponding to bin edge $l$. \\
\hline$D_{l}$ & Daily mileage for EVs in bin edge $l$. \\
\hline$b^{w}$ & Bin width in $\mathrm{km}$, used for daily mileage of vehicles. \\
\hline$E_{n}$ & Daily energy consumption of EV $n$. \\
\hline$E_{n}^{p k m}$ & Energy consumption per $\mathrm{km}$ of $\mathrm{EV} n$ in Wh. \\
\hline$E_{n}^{a} h, E_{n}^{a w}$ & Excess amount of energy available in EV $n$ at home and workplace, respectively. \\
\hline$E_{n}^{r h}, E_{n}^{r w}$ & Amount of energy available in EV $n$ at home and workplace at arrival time, respectively \\
\hline $\mathrm{SoC}_{n}^{\min }$ & Preferred minimum level of SoC for EV $n$. \\
\hline$B_{n}^{c a p}$ & Useable battery size (capacity) of EV $n$. \\
\hline$\alpha_{n}$ & $\begin{array}{l}\text { Used to define the desired amount of reserve energy for EVs in the workplace for } \\
\text { upcoming tasks. }\end{array}$ \\
\hline$E_{t}^{\text {Raas }}$ & Amount of energy available to be used for RaaS during any interval $t$. \\
\hline$\beta$ & $\begin{array}{l}\text { Used to determine the ratio of home-based EVs and workplace-based EVs for } \\
\text { mixed buildings. }\end{array}$ \\
\hline$\gamma^{\text {Raas }}$ & The ratio of EVs willing to participate in RaaS. \\
\hline$V_{\beta}$ & The proposed variation index. \\
\hline$E_{\beta, \text { max }}^{\text {Ras }}, E_{\beta, \text { min }}^{\text {Raas }}$ & The maximum and minimum amount of energy available for RaaS, respectively. \\
\hline$\mu_{\beta}^{\text {Raas }}, \sigma_{\beta}^{\text {Raas }}$ & Mean and standard deviation of energy available for RaaS, respectively. \\
\hline
\end{tabular}




\section{References}

1. Campbell, R.J. CRS Report for Congress: Weather-Related Power Outages and Electric System Resiliency. 2012. Available online: https:/ /sgp.fas.org/crs/misc/R42696.pdf (accessed on 3 December 2021).

2. Wang, Y.; Chen, C.; Wang, J.; Baldick, R. Research on Resilience of Power Systems under Natural Disasters-A Review. IEEE Trans. Power Syst. 2016, 31, 1604-1613. [CrossRef]

3. Faraji, J.; Babaei, M.; Bayati, N.; Hejazi, M.A. A comparative study between traditional backup generator systems and renewable energy-based microgrids for power resilience enhancement of a local clinic. Electronics 2019, 8, 1485. [CrossRef]

4. A Case Study on Emergency Backup Power with Renewable Energy. Available online: https://sustain.ubc.ca/about/resources/ case-study-emergency-backup-power-renewable-energy (accessed on 3 December 2021).

5. Alberta Utilities Commission. Waterton Battery Energy Storage System. 2021. Available online: https:// efiling-webapi.auc.ab.ca/ Document/Get/683303 (accessed on 3 December 2021).

6. Li, J.; Niu, D.; Wu, M.; Wang, Y.; Li, F.; Dong, H. Research on Battery Energy Storage as Backup Power in the Operation Optimization of a Regional Integrated Energy System. Energies 2018, 11, 2990. [CrossRef]

7. HSB. Maintaining Emergency and Standby Engine-Generator Sets. 2020. Available online: https://www.munichre.com/content/ $\mathrm{dam} /$ munichre/global/content-pieces/documents/447-Recommended-Practice-for-Maintaining-Emergency-and-StandbyEngine-Generator-Sets.pdf/_jcr_content/renditions/original.media_file.download_attachment.file/447-RecommendedPractice-for-Maintainig-Emergency-and-Standby-Engine-Generator-Sets.pdf (accessed on 13 January 2022).

8. International Energy Agency. Global EV Outlook 2021 Overview; International Energy Agency: Paris, France, 2021.

9. Electric Vehicle Database Useable battery capacity of fully electric vehicles cheatsheet-EV Database. Available online: https: / / ev-database.org/cheatsheet/useable-battery-capacity-electric-car (accessed on 3 December 2021).

10. Li, X.; Tan, Y.; Liu, X.; Liao, Q.; Sun, B.; Cao, G.; Li, C.; Yang, X.; Wang, Z. A cost-benefit analysis of V2G electric vehicles supporting peak shaving in Shanghai. Electr. Power Syst. Res. 2020, 179, 106058. [CrossRef]

11. Yoo, Y.; Al-Shawesh, Y.; Tchagang, A. Coordinated control strategy and validation of vehicle-to-grid for frequency control. Energies 2021, 14, 2530. [CrossRef]

12. Haghi, H.V.; Qu, Z. A Kernel-Based Predictive Model of EV Capacity for Distributed Voltage Control and Demand Response. IEEE Trans. Smart Grid 2018, 9, 3180-3190. [CrossRef]

13. Agarwal, L.; Peng, W.; Goel, L. Using EV battery packs for vehicle-to-grid applications: An economic analysis. In Proceedings of the 2014 IEEE Innovative Smart Grid Technologies-Asia (ISGT ASIA), Kuala Lumpur, Malaysia, 20-23 May 2014; IEEE Computer Society: Piscataway Township, NJ, USA, 2014; pp. 663-668.

14. Kataoka, R.; Ogimoto, K.; Iwafune, Y. Marginal Value of Vehicle-to-Grid Ancillary Service in a Power System with Variable Renewable Energy Penetration and Grid Side Flexibility. Energies 2021, 14, 7577. [CrossRef]

15. Van Heuveln, K.; Ghotge, R.; Annema, J.A.; van Bergen, E.; van Wee, B.; Pesch, U. Factors influencing consumer acceptance of vehicle-to-grid by electric vehicle drivers in the Netherlands. Travel Behav. Soc. 2021, 24, 34-45. [CrossRef]

16. Hussain, A.; Musilek, P. A Reward Mechanism for Reliability-as-a-Service Usage of Electric Vehicles. In Proceedings of the 13th IEEE Conference on Innovative Smart Grid Technologies (ISGT 2022), Washington, DC, USA, 21-24 February 2022; Available online: https:/ / era.library.ualberta.ca/items/383d89bb-c29b-4fbc-b683-769c6483fb91 (accessed on 3 December 2021).

17. National Household Travel Survey. Available online: https://nhts.ornl.gov / downloads (accessed on 3 December 2021).

18. Energy Consumption of Full Electric Vehicles Cheatsheet-EV Database. Available online: https://ev-database.org/cheatsheet/ energy-consumption-electric-car (accessed on 3 December 2021).

19. Yang, W.; Xiang, Y.; Liu, J.; Gu, C. Agent-Based Modeling for Scale Evolution of Plug-in Electric Vehicles and Charging Demand. IEEE Trans. Power Syst. 2018, 33, 1915-1925. [CrossRef]

20. Nie, Y.; Chung, C.Y.; Xu, N.Z. System State Estimation Considering EV Penetration with Unknown Behavior Using Quasi-Newton Method. IEEE Trans. Power Syst. 2016, 31, 4605-4615. [CrossRef]

21. Gong, H.; Ionel, D.M. Optimization of aggregated EV power in residential communities with smart homes. In Proceedings of the 2020 IEEE Transportation Electrification Conference and Expo, ITEC 2020, Chicago, IL, USA, 23-26 June 2020; Institute of Electrical and Electronics Engineers Inc.: Piscataway Township, NJ, USA, 2020; pp. 779-782.

22. U.S. Department of Transportation. 2017 NHTS Data User Guide; Federal Highway Administration Office of Policy Information: Washington, DC, USA, 2018; Volume 2018.

23. Zhang, P.; Qian, K.; Zhou, C.; Stewart, B.G.; Hepburn, D.M. A methodology for optimization of power systems demand due to electric vehicle charging load. IEEE Trans. Power Syst. 2012, 27, 1628-1636. [CrossRef] 